\title{
A Política Internacional, a Conjuntura Econômica e a Argentina de Néstor Kirchner
}

\author{
International politics, the economic conjuncture and Néstor \\ Kirchner's Argentina
}

JAVIER ALBERTO VADELL *

Rev. Bras. Polít. Int. 49 (1): 194-214 [2006]

\section{Introdução}

Em 25 de maio de 2003, o ex-governador da província patagônica de Santa Cruz, Néstor Kirchner - do Partido Justicialista (peronista) - assumiu a Presidência da República Argentina, após uma profunda convulsão política. Esse acontecimento deu término ao impasse institucional decorrente da crise econômica e política que derrubou, por pressão e protesto social, o ex-presidente da Aliança (União Cívica Radical, Frepaso ${ }^{1}$ e outros partidos políticos) Fernando De la Rúa. Kirchner ganhou as eleiçôes após o ex-presidente Carlos Menem desistir de concorrer ao segundo turno, apesar de este último ter vencido o primeiro turno ${ }^{2}$ com $24,36 \%$ dos votos válidos contra $22 \%$ de Kirchner. As pesquisas e projeçôes indicavam um triunfo de Kirchner com mais de quarenta pontos de diferença no segundo turno.

O fato de ter assumido a presidência argentina com apenas $22 \%$ dos votos obrigou o governo Kirchner a avaliar as eleições legislativas de outubro de 2005 como um verdadeiro plebiscito de apoio ou não a seu governo. Segundo uma pesquisa do Centro de Estudios de Opinión Pública (CEOP), e divulgada pelo jornal Clarin $^{3}$ em maio de 2005, o presidente Kirchner acabou seu segundo ano de governo com um amplo apoio da população: $77,9 \%$ de imagem positiva pessoal e $63,7 \%$ de aprovação ao conjunto da sua gestão presidencial. Três

\footnotetext{
* Professor do Departamento de Relações Internacionais da Pontifícia Universidade Católica de Minas Gerais - PUC Minas (javier.vadell@pucminas.br).

${ }^{1}$ Cujo líder foi Carlos Alvarez (Chacho), que renunciou ao cargo de vice-presidente durante o mandato de De la Rúa.

2 Carlos Menem, 24,36 \% (Alianza por la Lealtad); Nestor Kirchner, 22\% (Alianza frente para la Victoria). Ambos do Partido Justicialista (peronista). Para ver os resultados completos das eleições ver: <http://www.terra.com.ar/ctematicos/elecciones2003/68/68112.html>

3 Jornal Clarin, 22.5.2005.
} 
aspectos foram elogiados segundo a pesquisa: a renegociação da dívida externa, a política econômica em geral e a política externa do país. O resultado das eleiçôes para deputados e senadores de outubro de 2005 fortaleceu o apoio de amplos setores da população argentina ao governo peronista e à figura do presidente Kirchner tanto no espectro político nacional - manteve uma amplia maioria no Congresso - como dentro do próprio Partido Justicialista derrotando os principais rivais: Eduardo Duhalde, na província de Buenos Aires e Carlos Menem na província de La Rioja.

Após a crise política e econômica de 2001, a renegociação da dívida externa ${ }^{4}$, por meio de um acordo com o Fundo Monetário Internacional (FMI) e com os credores internacionais, tornou-se prioridade do governo de transição de Duhalde (2002-2003) e do governo eleito de Kirchner. A partir de 2002, a economia argentina começou a dar sinais positivos de recuperação, atingindo um crescimento de mais de 8\% do Produto Interno Bruto (PIB) em 2003. Em política externa, a gestão Kirchner, como tinha sido com os governos anteriores, esteve pautada, em grande medida, pelas dificuldades econômicas e financeiras.

Deste modo, o objetivo principal deste artigo é analisar a política externa da Argentina, à luz das transformações da política internacional e do contexto econômico global. O trabalho parte da premissa de que o ano 2001 marcou um ponto de ruptura no sistema internacional, em dois níveis. O primeiro nível, com os atentados terroristas de 11 de Setembro, no qual a potencia unipolar, os Estados Unidos da América (EUA), assumem a liderança da denominada "Luta contra o Terror". A percepção de um sistema internacional unipolar, a partir desse momento, se mostra mais evidente do que nunca (WOHLFORTH, 1999). O segundo nível está relacionado ao desencantamento do modelo de desenvolvimento neoliberal econômico, alentado e promovido pelas instituições econômicas internacionais. Nesse sentido, a crise argentina de 2001 apresenta-se como um caso paradigmático.

Assim, no artigo levanta-se uma hipótese mais geral, à luz da realidade política dos primeiro anos do século XXI. No sistema unipolar atual, e especialmente após os atentados terroristas de 11 de Setembro, os países em desenvolvimento (aqueles que não estiverem implicados com as novas ameaças: a luta contra o terrorismo e a produção de armas de destruição em massa) adquirem maior margem de manobra política, levando em consideração, também, uma variável interveniente, que é a conjuntura econômica favorável, principalmente a partir de 2002. Ou seja: em primeiro lugar, no comércio internacional, os altos preços internacionais das commodities beneficiam os países

${ }^{4}$ A moratória da dívida externa foi declarada pelo ex-presidente Rodríguez Saa, que sucedeu Antonio De la Rúa e ficou menos de um mês no poder. O fugaz mandatário foi sucedido por Eduardo Duhalde. 
exportadores desses produtos; em segundo lugar, a política de juros baixos ${ }^{5}$ dos EUA e de liquidez internacional favorecem a entrada de capitais nos países emergentes (MOFFETT, 2004).

Essa hipótese mais geral ajudará na compreensão de processos políticos de mudança que estão acontecendo na América Latina. Com a eleição para presidente de Evo Morales na Bolívia, há de fato uma tendência ao revisionismo crítico dos programas liberalizantes pró-mercado aplicados nas décadas de 1980 e 1990. Em alguns países esse revisionismo foi mais radical do que em outros, ainda ressurgindo, como no caso da Bolívia, com demandas sociais históricas de participação democrática e de integração social da maioria da população de origem indígena.

A Argentina atual não foge dessa tendência. Após uma crise econômica e política profunda, em 2002, o país começou a se recuperar rapidamente, atingindo altas taxas de crescimento por três anos consecutivos, e com projeçóes de continuidade. Em outros termos, a Argentina, assim como outros países em desenvolvimento, está aproveitando essa margem de manobra, re-avaliando criticamente as reformas neoliberais implementadas nos anos 90, seja pelas respostas pragmáticas de políticas públicas no plano doméstico, como por meio de uma posição mais crítica face às instituições internacionais de crédito. Essa mudança de posicionamento está também amparada conjunturalmente, como se salientou, pelo contexto econômico internacional. Nessa direção, antes de ingressar na política externa da Argentina do governo Kirchner, é mister repassar a história argentina recente.

\section{A Argentina nos anos 90}

Carlos Menem, do Partido Justicialista, foi eleito presidente da Argentina em 1989 em meio a uma crise inflacionária e a uma crise social que se manifestou em diversos atos de violência, inclusive com saques em lojas e supermercados de duvidosa espontaneidade. O presidente Raúl Alfonsín, da União Cívica Radical (UCR), sem apoio político, teve que entregar o mandato alguns meses antes do previsto. Menem, ex-governador de La Rioja - província pobre do noroeste da Argentina -, com estilo de clássico caudilho regional, fez uma campanha política com o típico discurso populista do Partido Peronista.

As mudanças no contexto internacional pressagiavam profundas transformaçôes na esfera doméstica dos estados nacionais e principalmente nas nações em desenvolvimento. Com a desintegração da União Soviética em começos dos anos 90, os EUA se configuravam como o único líder econômico

5 O Banco Central estadunidense iniciou, em junho de 2004, uma política de ajustes graduais das taxas de juros, tendo feito desde então 14 aumentos de 0,25 pontos percentual cada. A taxa de juros passou assim de $1 \%$ para $4,5 \%$. 
e político num sistema unipolar (WOLHFORTH,1999) ${ }^{6}$. Alguns intelectuais otimistas, como Francis Fukuyama, prenunciavam um futuro no qual a democracia liberal iria se espalhar por todo o mundo. Nessa direção, no plano das idéias, o liberalismo econômico foi apresentado pelos centros de poder mundial - os EUA, as instituições econômicas internacionais, grandes bancos, corporações transnacionais, e investidores financeiros - como a solução para todos os males e vícios dos países ex-socialistas reais e subdesenvolvidos. Esses centros de poder agiram articuladamente, recomendando e condicionando ajudas financeiras à adoção de políticas econômicas liberalizantes. Tal articulação ficou conhecida como "Consenso de Washington", termo cunhado por Williamson (1990).

Face às mudanças estruturais no plano internacional, o governo Menem se apoiou, fundamentalmente, em dois grandes pilares, que sustentaram uma política exterior pautada, essencialmente, em termos de política econômica. O primeiro pilar da política externa foi conhecido como o princípio das relações especiais ou "relaçôes carnais", que não significa outra coisa que uma relação estreita e preferencial com a potência vencedora da Guerra Fria, os EUA. O sustento teórico, e ideológico, dessa posição é dado pelo analista de Relações Internacionais, e ex-funcionário do governo Menem, Carlos Escudé, na polêmica expressão "realismo periférico" (ESCUDÉ, 1997). A noção realismo periférico supõe que, reconhecida a hegemonia dos Estados Unidos, a Argentina deveria ter um alinhamento automático visando a obter benefícios, que, de outra maneira, não obteria. Em outras palavras, esse realismo estabelece o "alinhamento com os Estados Unidos, entendido em termos de aceitação realista da liderança norte-americana no hemisfério Ocidental"

Outros analistas críticos a esta postura afirmam que o realismo não implica, a partir das relações de poder existentes, uma "submissão automática nem aceitação do papel menor e subordinado para um país periférico sem se

\footnotetext{
${ }^{6}$ Nos anos 90, aconteceu na academia estadunidense um debate em torno da unipolaridade, sua especificidade e sua duração. Para mais detalhes ver: Krauthammer, Charles, "The Unipolar Moment", Foreign Affairs, vol.70. No 1, 1900-1991, p. 23-33; Layne, Cristopher, "The Unipolar Illusion: why great powers will rise", International Security, 17 (4) Spring, 1993, p. 5-51; e Wohlforth (1999); Waltz, Kenneth N. "Structural realism after the Cold War". in: International Security vol. 25 n. 1, Summer, 2000 , p. 5-41. Segundo estes autores unipolaridade não é hegemonia, que tem outras implicaçōes conceituais. A noção hegemonia, aplicada às relações internacionais, difere de acordo às abordagens adotadas. Por exemplo, hegemonia segundo o "realismo ofensivo" de Mearsheimer (2001:40-42) significa a dominação do sistema, que pode ser interpretada como uma dominação mundial. Esta situação implica a existência de um hegemon, que seria o único grande poder no sistema. "Um Estado que é substancialmente mais poderoso que os outros grandes poderes no sistema não é um hegemon, porque enfrenta, por definição, outros poderes" (MEARSHEIMER.2001:40). O conceito de hegemonia implica aqui uma quase situação ideal. Na realidade seria uma espécie de império.

7 "Relações carnais" com os Estados Unidos, termo cunhado pelo ex-chanceler argentino Guido Di Tella.Em entrevista ao jornal Página12, em 9 de dezembro de 1990, o ex-chanceler expressou: "Yo quiero tener una relación cordial con Estados Unidos y no queremos un amor platónico. Nosotros queremos un amor carnal con Estados Unidos, nos interesa porque podemos sacar un beneficio". Na análise, preferiu-se o termo "relações especiais", utilizado por Corigliano (2003).

${ }^{8}$ Escudé, citado por Aranda (2004).
} 
questionar o tipo de relação com os EUA nem os fundamentos do sistema internacional." " A partir dessa diretriz ideológica, o governo Menem tomou um conjunto de decisões que implicaram uma mudança de rumo em relação a seu passado recente.

Segundo Aranda (2004), o "realismo periférico" significa a "política exterior de um estado comercial. Um Estado que põe ênfase na especialização econômica a partir da suas vantagens comparativas, o qual significa, para o Estado argentino, a consolidação do modelo agro-exportador provedor de matérias primas e produtos de escasso valor agregado..." (ARANDA, 2004, p.8). Por outro lado, Tokatlian (2004, p.159) afirma que o modelo de política externa dos anos 90 não se fundamentou numa posição realista das relações internacionais. "Pelo contrário, a Argentina optou por um comportamento irrealista”. Em primeiro lugar, o modelo teve como condição um pressuposto não realista: "que um alinhamento externo brindaria ao país a possibilidade de recuperar e acrescentar o seu poder". Em segundo lugar, a Argentina se caracterizou por um "estilo diplomático no qual primou a sobre-atuação e as atitudes de free riding". Em terceiro lugar, afirma Tokatlian, a Argentina teve uma diplomacia ingênua. "A elite confiou de maneira excessiva em que as forças de mercado, e não o poderio do Estado, iam conseguir inserir o país num lugar de privilégio no mundo" (TOKATLIAN,2004, p.159) ${ }^{10}$.

A redefinição da política externa da Argentina teve como ponto de partida o restabelecimento de relações diplomáticas com o Reino Unido ${ }^{11}$, que foi considerado como condição essencial para o estabelecimento de uma nova relação com os EUA (SARAIVA e TEDESCO, 2001). Nessa direção outras decisōes foram tomadas que visavam sobretudo a uma aproximação com os EUA. Como exemplo, pode-se destacar: 1) a participação Argentina na Guerra do Golfo (1991) contra o Iraque, por meio do envio de dois navios de guerra - sem consultar previamente o Congresso; 2) a mudança do voto favorável à investigação sobre Direitos Humanos em Cuba, promovido pelos EUA e por alguns países europeus. Assim, a Argentina se afastava da tradição de defesa do princípio da não-intervenção nos assuntos internos de outros Estados, e, neste caso específico, iria se opor às posições do México e do Brasil; 3) a retirada do movimento de Países Não-Alinhados, em 1991; 4) a desativação do Programa Missilístico Condor II; 5) a mudança do perfil do voto argentino na Assembléia das Naçôes Unidas, se aproximando das posturas estadunidenses (ARANDA, 2004; CORIGLIANO, 2003).

\footnotetext{
9 Raúl Bernal Meza, citado por Ananda (2004:8)

10 "A lógica da política externa de Menem sustentava-se numa nova hierarquia na qual a geração de recursos econômicos era mais importante que a geração de recursos político-militares" (ESCUDÉ, 1995, p.171).

11 As relações estavam rompidas desde a Guerra das Malvinas em 1982.
} 
O segundo pilar da política exterior de Menem foi a aceitação, quase que incondicional, do paradigma neoliberal econômico. Uma vez no poder, Carlos Menem implementou um dos mais ousados programas de reformas liberalizantes pró-mercado, baseado, principalmente, em cinco políticas: 1) a privatização das empresas públicas; 2) a abertura comercial; 3) a liberalização financeira; 4) as reformas trabalhistas; e 5) o programa de estabilização, a partir de uma taxa de câmbio fixa: uma aposta do então ministro da Economia Domingo Cavallo para estabilizar a economia do país e deter o processo inflacionário. Isso aconteceu com a "lei de convertibilidade" de abril de 1991, que estabeleceu que, a partir daquele momento, 10.000 australes passariam a valer 1 peso. Essa nova moeda argentina teria, por lei, uma relação fixa com o dólar de 1 a 1 , ou seja, 1 dólar seria equivalente a um 1 peso. Esse sistema, denominado Currency Board, obrigava o Banco Central (BCRA) a manter dólares na reserva em relação ao peso circulante. Mudar a paridade significava ter que mudar uma lei, o que requereria uma maioria no Congresso.

A lei teve relativo sucesso no começo, principalmente no que concerne a acabar com a alta inflação, o que provocou expectativas positivas na população em geral e nos investidores privados, nacionais e estrangeiros, que viam na Argentina, como país emergente, uma boa oportunidade de investimentos ${ }^{12}$. Porém, os primeiros problemas surgiram em 1995. A Argentina sofreu o impacto da crise econômica de dezembro de 1994 no México, o que provocou a saída de capitais e mostrou a fragilidade de programa econômico baseado no Currency Board e na abertura indiscriminada da economia. O governo Menem, com o ministro de Economia Cavallo, e seu sucessor, Roque Fernández, não modificou as diretrizes da política econômica. Em finais de 98, a economia argentina começou a entrar numa espiral de queda (HASLAM, 2003; SCHVARZER, 2004). O círculo vicioso de déficits crescentes e confiança em declínio mostrouse impossível de ser quebrado (HASLAM, 2003; FISHER, 2001).

Além dessas variáveis da economia doméstica, o contexto externo não se mostrou favorável. "O declínio dos termos do comércio para as exportações argentinas, o impacto da crise da Rússia em agosto de 1998 e a desvalorização da moeda brasileira, em janeiro de 1999, as taxas de juros subindo e a sobrevalorização do peso devido à conversibilidade minaram o crescimento e a capacidade do governo para equilibrar o orçamento" (HASLAM, 2003, p.4). A sobrevalorização da moeda, acompanhada de um programa de abertura

\footnotetext{
12 Schwarzer (2004) afirma que: "a convertibilidade provocou um enorme alívio social, semelhante ao ocorrido no auge do Plano Austral (em 1985 com o Presidente Alfonsín) e pelo mesmo motivo: a estabilidade de preços, que oferecia um ponto de referência e segurança. É claro que a aceitação social baseava-se na experiência cotidiana e não em critérios teóricos. $\mathrm{O}$ processo desgastante de inflação elevada que em média havia se mantido na ordem de $300 \%$ ao ano durante quase 16 anos (e sem baixar de $100 \%$ em nenhum ano desse período) tinha gerado uma exigência potencial pela estabilidade de preços que nem sempre havia sido reconhecida como tal." (SCHVARZER, 2004, p. 30-31).
} 
comercial na Argentina, favoreceram as importações. Assim, a balança comercial de bens e serviços foi negativa em praticamente todo o período que durou a conversibilidade.

Em relação à política regional, deve-se destacar o processo de integração econômica com o Brasil, Uruguai e Paraguai. O governo Menem aprofundou as relações entre esses países, dando continuidade à iniciativa dos governos de Alfonsín e Sarney de criação de um bloco econômico regional, e especialmente depois da assinatura do Tratado de Assunção, em 1991, e a criação do Mercado Comum do Sul (Mercosul). Assim, o Mercosul foi criado e conformado no contexto do auge dos programas econômicos liberalizantes ${ }^{13}$. Na Argentina o processo de integração com o Brasil foi um consenso dentro dos partidos políticos. Entretanto, a visão da integração regional para o governo Menem, e especialmente para o ex-ministro Cavallo, foi a de um Mercosul como um primeiro passo em direção a uma liberalização mais ampla, à "globalização". Nesse sentido, a Área de Livre Comércio das Américas (Alca), o programa de integração hemisférica de livre comércio impulsionado pelo governo George Bush, e depois pelo governo Clinton, estaria em harmonia com o Mercosul idealizado pelos formuladores de política do governo Menem $^{14}$.

\section{A Aliança, seu ocaso e a transição: mudança ou continuidade?}

Em 10 de dezembro de 1999, o Governo da Aliança, do pesidente Fernando de la Rúa e do vice Carlos (Chacho) Alvarez, assumiu o poder após dez anos de governo peronista. A Aliança estava principalmente comprometida com a "necessidade de infundir transparência à vida institucional do país, arrasado pela corrupção que a opinião pública associava com o governo anterior" (ROMERO e TORRES, 2004, p. 9). Segundo Aranda (2004), três elementos fundamentais podem explicar a debilidade política desse governo. O primeiro diz respeito às condiçôes de governabilidade. De la Rúa chegou ao governo sabendo que teria que enfrentar um Senado com imensa maioria peronista. Além disso, teve que administrar um país com 17 províncias governadas também pelo peronismo, dentre elas as mais importantes econômica e politicamente: Buenos Aires, Santa Fé e Córdoba. O segundo fator é constituído pelas próprias características pessoais do ex-presidente De la Rúa. A falta de liderança e carisma fazia dele um presidente dependente de outros líderes partidários e de um círculo familiar e de amigos fechado que influenciava suas decisōes. O terceiro

\footnotetext{
13 Para a Argentina, o mercado brasileiro se apresentava como uma ótima alternativa para exportação, tendo em conta que depois de aplicada a conversibilidade a Argentina passou a sofrer déficit na balança comercial de 2.637 bilhōes de US\$ em 1992; 2.364 bilhões em 1993; e 4.139 bilhōes em 1994. Fonte: Ministério de Economia da República Argentina.

${ }^{14}$ Essa posição era defendida na época, principalmente, pelo ministro de Economia, Domingo Cavallo e também pelo ministro de Relações Exteriores Guido Di Tella.
} 
acontecimento que enfraqueceu ainda mais esse governo foi a renúncia do vice-presidente, por um acontecimento de corrupção e subornos no Senado, no tratamento da lei de reforma trabalhista (ARANDA, 2004).

Em política externa, o governo da Aliança manteve as linhas gerais da gestão peronista, embora o ministro de Relações Exteriores desse governo, o economista Rodríguez Giavarini, expressasse, em 1999, que o novo caminho escolhido pelos cidadãos favorecia a ampliação da democracia, e que os "interesses primordiais" do país seriam "a integração política e econômica sulamericana como objetivo central; o afiançamento da paz e da segurança internacionais e a democratização do sistema internacional ${ }^{15}$ ". Segundo BernalMeza, dos primeiros discursos do governo da Aliança podiam se perceber dois elementos norteadores da política externa: "a integração (Mercosul, América do Sul) e a posição a respeito de uma visão mais bem ética e normativa do sistema internacional” (BERNAL-MEZA, 2002, p.80).

Não obstante as intenções do governo da Aliança de se apresentar como diferente em relação à gestão Menem, a política externa argentina manteve-se pautada, em grande medida, pela política econômica, apoiada internacionalmente pelos EUA, de quem Argentina dependeu para obter uma "blindagem" de 40 bilhões de dólares para enfrentar os novos acordos com o FMI, e para renegociar as dívidas de curto prazo com a banca privada internacional.

Divergências com o Brasil se superariam nos primeiros anos do mandato De la Rúa por meio dos acordos de coordenação macroeconômica, referenciados nas estatísticas harmonizadas, assinados no encontro do Mercosul realizado na cidade de Florianópolis em dezembro de $2000^{16}$. Entretanto, em fevereiro de 2001, com o retorno de Cavallo ao Ministério da Economia, as relações entre Brasil e Argentina deteriorar-se-iam de maneira profunda. $\mathrm{O}$ ex-ministro de Menem era uma pessoa mais próxima dos EUA, com posturas pró-Alca e a favor de um acordo bilateral com a potência do Norte.

A situação econômica era muito delicada e o país sofria, desde 1998, uma recessão que parecia não ter fim. De la Rúa se comprometeu, durante a campanha política e no governo, a manter a conversibilidade do peso em relação ao dólar. $\mathrm{O}$ resultado foi a aplicação de políticas de ajuste econômico, recessivas e deflacionárias, muito prejudiciais para a maioria dos segmentos das classes médias e baixas da população argentina. No primeiro ano e meio, o governo De la Rúa aplicou três grandes ajustes que, em alguns casos, contemplavam a redução nominal do salário dos funcionários públicos.

Após uma década de reformas econômicas liberalizantes (privatizações de empresas públicas, abertura comercial e financeira indiscriminada e

\footnotetext{
15 Citado por Bernal-Meza (2002, p.80).

16 Deve-se ter presente da importância que representava o Brasil em termos comerciais para a Argentina, principalmente nesse período de fragilidade econômica. Brasil era o principal comprador de produtos argentinos experimentando déficit na balança comercial com o país platino desde 1995 até 2002.
} 
flexibilização das leis trabalhistas) aplicadas pelo governo peronista de Carlos Menem e continuada pelo governo De la Rúa, a Argentina em 2001 atingiu sua pior crise econômica desde o anos trinta. $\mathrm{O}$ sistema financeiro em falência, fuga de capitais, a restrição aos saques de depósitos bancários - Corralito - e a economia tecnicamente quebrada foram o telão de fundo das manifestações sociais que se multiplicavam dia a dia ao ritmo da crise.

O colapso da economia argentina, em dezembro de 2001, provocou a renúncia do presidente De la Rúa, depois de massivos protestos e a posterior repressão dos manifestantes, deixando dezenas de vítimas. Esse foi o marco político da crise institucional, na qual em dez dias sucederam-se quatro presidentes provisórios. Finalmente, o Congresso chegou a um acordo e o exgovernador da província de Buenos Aires, o senador Eduardo Duhalde foi empossado como Chefe de Estado. Nesse curto período de transição, declarouse a moratória unilateral da dívida externa com os credores privados - na curta gestão de Rodríguez Saá - e se acabou com a conversibilidade monetária, já no governo Duhalde.

O impacto social das crises da segunda metade dos anos 90 foi dramático para a sociedade argentina. Alguns dados mostram o grau de seriedade da situação social do país. O desemprego aberto superou, em 2002, 20\% da população ativa, o PIB tinha declinado numa taxa anual de $16,3 \%$ durante o primeiro trimestre de 2002, o que representou um recorde. Os salários reais abaixaram 18\% durante o decorrer desse ano. As taxas de pobreza e de indigência chegaram a níveis nunca antes vistos: os dados do governo indicam que 53\% dos argentinos viviam abaixo da linha de pobreza, sendo $25 \%$ da população indigente (necessidades básicas não satisfeitas). Entre 1998 e 2002, elevou-se a pobreza extrema em $223 \%$ na Argentina. Um fato único num espaço de tempo tão reduzido. Em 2001, a participação dos trabalhadores no PIB caiu ao nível mais baixo da história argentina.

\section{O governo Kirchner}

A política exterior menemista foi mais prolongada que o governo Menem. A Aliança manteve as diretrizes principais da política econômica, com a manutenção da conversibilidade e os programas de ajuste e da política externa. Assim, Domingo Cavallo, o "pai da conversibilidade", regressou ao Ministério da Economia na última etapa do breve governo de Fernando de la Rúa. Nesse sentido, Tokatlian (2005a) aponta que as mudanças significativas se dão durante o governo de Néstor Kirchner, tanto em relação à política exterior como na maneira de ver a economia. Essas transformações estão baseadas, segundo o autor, em três realidades:

1) A primeira é a percepção da sociedade e do governo do enorme fracasso que significou a política externa das "relações especiais" com os centros de 
poder político internacional (Washington) e com os centros de poder financeiro, especificamente o FMI e o Banco Mundial. O Estado argentino, por mais ou menos uma década, foi mostrado ao mundo pelas instituições financeiras e pelos investidores privados como o aluno exemplar do FMI. Contudo, quando atravessava sua pior crise, não obteve ajuda, resgate, apoio ou solidariedade por parte desses centros de poder econômico.

2) $\mathrm{O}$ segundo elemento que ajudou a interpretar a mudança refere-se ao fato de que, dada a debilidade do mandato Kirchner, o presidente viu-se obrigado a dar claros sinais de assertividade e de determinação. Além disso, o presidente tem um apelo fortemente pessoal, intempestivo e pouco adepto aos protocolos, o que reforça o caráter personalista do mandato.

3) Um terceiro elemento seria a formação política e as características próprias da geração do presidente. "É um filho da geração dos anos 1970, que tem uma visão marcada por um momento histórico de mudança”. Segundo Corigliano (2004), há influência de um passado de peronismo "setentista", de identificação ideológico-simbólica com regimes reformistas de caráter ideológico anti-imperialista. Essa visão "procura resgatar em forma simbólica idéias e gestos reformistas próprios da esquerda peronista na que militaram, em sua juventude, o presidente Kirchner e seu (primeiro) Chanceler Rafael Bielsa" (CORIGLIANO, 2004).

Deste modo, dois aspectos valem a pena destacar do curto período do governo Kirchner. Em primeiro lugar, a resolução da saída da moratória por meio de uma difícil negociação com os credores privados e, em concomitância, com o FMI. A Argentina saiu da incômoda condição de moratória, conseguindo acordos aparentemente mais vantajosos que outros países em desenvolvimento e especialmente que o Brasil na negociação com o FMI. A reestruturação da dívida externa com os credores privados, em 2005, e a saída da situação de moratória (default) foram percebidas como um sucesso por grande parte de população. Isso possibilitou ao presidente Kirchner e ao ex-ministro da Economia Roberto Lavagna ${ }^{17}$ reinserir a Argentina na economia internacional. Em janeiro de 2005, o governo argentino apresentou um programa de troca de uma parte da dívida com os credores privados argentinos e estrangeiros. Visando a esse objetivo, o governo emitiu novos bônus para substituir os que não foram pagos. Existiam mais de 150 tipos de bônus em moratória. Deu-se a oportunidade aos credores de escolher entre três novas categorias de bônus, sendo o prazo final, dado pelo governo argentino, em 25 de fevereiro. Depois dessa data, os credores que não aceitassem poderiam recorrer à Justiça ${ }^{18}$.

\footnotetext{
17 Roberto Lavagna, ex-funcionário do governo de Raúl Alfonsín, foi ministro de Economia do governo de transição de Duhalde e continuou na pasta da Economia sob mandato do presidente Kirchner

18 Para mais detalhes ver: Mendes Daniel "Renegociação da Dívida Argentina" in: www.pucminas.br/ conjuntura , 18 de março de 2005.
} 
Em 3 de março de 2005, o ministro Lavagna anunciou que 76,07\% dos credores privados, do total de 152 títulos da dívida argentina em moratória, concordaram com a proposta de quitação apresentada pelo governo Kirchner, apesar da perda em torno de $63 \%$ e $68 \%$ do valor original do bônus. A recuperação do crescimento da economia que tinha começado em 2002, inclusive em situação de moratória com os credores privados internacionais, fortaleceu o ministro Lavagna nas negociações face o FMI e os credores.

Em segundo lugar, as relações com o Brasil foram colocadas como uma prioridade da política externa do governo de transição de Duhalde e do governo de Kirchner. Na região do Cone Sul, os vínculos com o Brasil foram elevados ao status de relaçôes estratégicas, como ferramenta destinada a maximizar a margem de manobra da Argentina em relação aos Estados Unidos e frente à União Européia, especificamente nas negociaçooses comerciais internacionais e dentro da Organização Mundial de Comércio (OMC). Isso implica que a estratégia do governo argentino coloca as políticas de regionalização (fortalecimento do Mercosul) como elemento prioritário, inclusive como base para uma via de desenvolvimento alternativa à via pregoada pelo Consenso de Washington.

Assim, segundo a versão oficial do governo Kirchner, o Mercosul:

...es ante todo un proyecto político, un espacio de la ampliación de la autonomía estatal capaz de gobernar la inserción de nuestros paises en el mundo. Tenemos la convicción de que en el mundo actual no hay futuro para proyectos de desarrollo de alcance estrictamente nacional, y es por eso que damos a nuestro bloque de pertenencia un sentido mucho más abarcador que el de un simple acuerdo comercial (BIELSA et al. 2005, p. 49).

Neste sentido, essa estratégia política e econômica pretende se afastar, em grande medida, dos princípios do regionalismo aberto imperante na década de 1990, imbuída dos princípios econômicos liberais. Segundo Lima e Coutinho, o regionalismo aberto é uma expressão contraditória "já que o primeiro termo sinaliza uma preferência pela região, e o segundo nega ou qualifica esta mesma orientação" (LIMA e COUTINHO, 2006, p. 1). Deste modo, a região tem que ser uma plataforma para a abertura econômica, favorecendo os setores competitivos e financeiros, e não um empecilho para o processo de globalização.

A crise argentina de 2001 agiu como catalisadora das mudanças da política doméstica, reconfigurando as alianças entre setores sociais. No plano estritamente partidário, a ala esquerda do peronismo adquiriu maior peso, e se consolidou no poder com o presidente patagônico. O ex-ministro da Economia de Duhalde e de Kirchner, Roberto Lavagna, sempre esteve ligado aos setores produtivos dos pequenos e médios industriais. Essa virada "nacionalista" econômica teve efeitos na política regional. Assim, a visão de Duhalde/Kirchner em relação ao Mercosul se afasta dos postulados do "regionalismo aberto", que dependia mais dos agentes econômicos do mercado. Lima e Coutinho (2006) denominam esse novo regionalismo dos anos 2000 de regionalismo físico e 
energético. "A região retorna aos seus contornos geográficos tradicionais em função da confluência de dois processos no sistema internacional e que podem ser sintetizados na idéia de valorização política e física das regiōes" (LIMA e COUTINHO, 2006. p.3). Esse processo não está isento de contradiçōes já que as políticas nacionalistas podem colocar obstáculos aos processos de integração segundo o "novo" paradigma.

A desindustrialização argentina da década de 1990 - aprofundando um processo que começa no ano 1976 com a ditadura e com Martínez de Hoz na pasta da economia - e a maior competitividade internacional das indústrias brasileiras mostraram-se cruciais para entender os desdobramentos políticos no âmbito do Mercosul. Tanto o presidente Kirchner quanto os ex-ministros Lavagna e Bielsa tinham consciência dessa assimetria estrutural e, com o novo viés nacionalista/desenvolvimentista desse governo, o resultado não poderia ser outro que as ríspidas negociações em torno de interesses conflitantes dos diversos setores afetados no processo de integração com o Brasil. Analistas têm lido alguns gestos do presidente Kirchner ${ }^{19}$ em relação ao Brasil como uma tentativa de contestação da liderança brasileira na região. Entretanto, a rispidez no trato entre ambos os países seria mais o produto de diferenças de interesses, que tem se expressado e manifestado no âmbito do Mercosul através de diferentes demandas por parte de setores prejudicados no comércio intrabloco, que desde 2003 tem sido deficitário para a Argentina.

\section{O Sistema Internacional, a conjuntura econômica e a Argentina}

A Argentina tem perdido um enorme poder relativo na política internacional nos últimos 50 anos, e, como expressa Tokatlian (2005a), hoje "carece de instrumentos de influência real no sistema internacional". Esse autor salienta que: "um excesso de vontade de mudança não acompanhado dos recursos para realizar essa mudança pode acabar em fortes frustrações”, que as restriçóes externas se superam com uma grande estratégia internacional, e que o governo Kirchner carece dessa estratégia, apesar de existirem iniciativas, gestos e pronunciamentos. Segundo Tokatlian, uma estratégia para um país periférico para o século XXI: "deveria identificar as ameaças prováveis à segurança do Estado e da sociedade assim como os desafios ao bem-estar e à autonomia, e planejar as respostas políticas, econômicas, militares e de outro tipo para afrontar essas ameaças e desafios". (TOKATLIAN, 2004, p.27).

Dois fatores resultariam, segundo Tokiatlian, dessa falta de estratégia: o primeiro é que no governo Kirchner existe uma primazia das condiçôes de política interna para fazer política exterior. Isto está ligado com um segundo

19 Por exemplo, algumas ausências do presidente Kirchner em encontros internacionais, como a Reunião de Cúpula da Comunidade Sul-Americana de Naçôes realizada em dezembro de 2004 em Cuzco, Perú, ou o abandono antes do previsto da Cúpula América do Sul-Países Árabes realizada em Brasília, em maio de 2005. 
fator, ou seja, as principais negociações da Argentina com os vizinhos, no âmbito do Mercosul, com o FMI e com os credores privados (por meio da chancelaria e do Ministério da Economia) acabam se tornando âmbitos de ação personalizados na política externa. Tokatlian (2004) afirma que, em política externa, ou se tende à institucionalização ou à personalização. A conformação de uma estratégia está diretamente vinculada à institucionalização da política externa da Argentina. Essa personalização da política externa argentina, por meio de uma diplomacia presidencial, vem de longa data e, ainda hoje, continua a reger as negociaçôes mais importantes do país.

No que respeita ao papel da Argentina e da região no sistema internacional para o século XXI, Tokatlian afirma que, em primeiro lugar, para os Estados Unidos, após o 11 de Setembro, a América Latina passa a ter uma relevância estratégica bastante reduzida.

E, em segundo lugar que:

El efecto sobre un pais periférico del doble proceso constituido por una reforzada hegemonía hemisférica de Estados Unidos y la ascendente gravitación de nuevas modalidades de autoridad no estatal es considerable. Asi entonces, los márgenes de maniobra y el poder negociador de naciones como la Argentina están y a restringidos, más aún cuando a las enormes limitaciones externas se suma una dramática crisis interna (TOKATLIAN, 2004, p. 114).

É precisamente nesse ponto que discordamos com Tokatlian. Um país como Argentina, que em 2001 experimentou a pior crise econômica desde a Segunda Guerra Mundial, que mantém os traços clássicos de sua diplomacia presidencial liderados pelo maior partido político (Justicialista), e que realizou as profundas reformas liberalizantes apoiadas por uma aliança política entre os setores empresariais financeiros, das grandes corporações transnacionais e de alguns setores sindicais, conseguiu se recuperar tão rapidamente, tendo em consideração uma desvalorização traumática e a declaração da moratória unilateral em conjunção com a desconfiança unânime dos setores econômicos poderosos nacionais e internacionais. Qual é o sentido dessa menor margem de manobra política para a o hemisfério, após o 11 de Setembro de 2001, a qual Tokatlian se refere?

Longe de pretender, neste artigo, dar uma resposta acabada a essa questão, observa-se que os desdobramentos políticos da pós-crise mostraram uma outra realidade; maiores margens de manobra e recuperação relativamente rápida. Isso não implica necessariamente que exista uma relação causal direta entre a declaração de uma moratória por parte de um país periférico (acompanhada de uma forte desvalorização) e o crescimento e recuperação econômica de um país. Muitas outras variáveis têm que ser levadas em conta, e cada caso tem suas peculiaridades. De tal modo, dentre as variáveis relevantes que nosso artigo pretende destacar estão os fatores exógenos (estruturais e conjunturais) da política internacional, que ajudarão a compreender alguns desdobramentos políticos dos Estados da região e, especificamente, da Argentina do século XXI. 
Assim, a estrutura internacional unipolar age como um ambiente no qual as margens de manobra política são mais amplas para os países em desenvolvimento - que não estiverem diretamente envolvidos com o terrorismo ou a produção de armas de destruição em massa - do que no sistema bipolar. E, quiçá, mais ampla também que na década inercial de 1990, em que os países em desenvolvimento e os antigos aliados soviéticos, na sua maioria, apostaram nas soluções de livre mercado.

Por outro lado, Carlos Escudé (2004), entende esses constrangimentos sistêmicos como uma "desordem global", ou como um problema de "crescente ingovernabilidade" da atual ordem mundial unipolar. Escudé também se refere a um "caos sistêmico", caracterizado pelo fato de ter contribuído para a redução dos custos na confrontação com a potência hegemônica. A maior margem de manobra é explicada pelos desajustes da ordem, por uma "crise de governança" (ESCUDÉ, 2004).

A nossa hipótese, porém, é que a redução dos custos na confrontação com os Estados Unidos se dá devido às mudanças na estrutura política internacional nos anos 90, e não a um hipotético "caos sistêmico". Além disso, o esgotamento do modelo de desenvolvimento neoliberal junto com os atentados terroristas de 11 de Setembro de 2001 reforçaram essa tendência e a percepção de que a ordem unipolar pode ter longa duração. Nesse sentido, a Argentina do presidente Néstor Kirchner deparou-se com um quadro complexo, porém extremamente favorável.

1. Em primeiro lugar, como foi destacado, as condiçóes estruturais são favoráveis. No sistema unipolar, os Estados não diretamente envolvidos nas "novas" ameaças podem desfrutar de uma maior margem de manobra ou autonomia relativa. Geopoliticamente, essa afirmação também é válida para a região da América Latina, que não está entre as prioridades em matéria de segurança por parte dos EUA na "Guerra contra o Terror".

2. Em segundo lugar, também a conjuntura econômica internacional é extremamente positiva. Dados do FMI mostram que a conjuntura econômica internacional mostrou-se excepcionalmente favorável, na medida em que "há um crescimento sincronizado da economia mundial" de 5,1\% em 2004, taxa recorde desde $1976^{20}$. E "no âmbito dos países em desenvolvimento, o crescimento estimado é ainda maior - cerca de 7,2\%, taxa mais elevada em trinta anos" (SINGH, 2005). A conjuntura dos mercados financeiros também é muito favorável, segundo o relatório de outubro de 2005 do FMI para América Latina e, junto com isso, as taxas de juros de longo prazo se encontram em seus mínimos históricos (SINGH, 2005). Por essas razões,

a liquidez tem sido abundante, os mercados de valores são dinâmicos e a busca de rendimentos continua contribuindo para que os ativos de mais alto risco continuem se valorizando. Portanto, as condiçôes de financiamento nos mercados emergentes têm

${ }^{20}$ Ver Moreira Cunha e Ferrari (2005) e Singh (2005). 
sido muito boas, e a maioria dos países desses mercados têm começado a financiar antecipadamente as necessidades de 2006 (SINGH, 2005).

Em relação ao comércio mundial, houve uma expansão. Nessa conjuntura, os preços dos produtos primários (commodities) experimentaram uma considerável elevação: produtos como a soja, carne, trigo, milho e o petróleo constituem itens importantes na pauta de exportação argentina - e de grande parte dos países de América Latina ${ }^{21}$. O PIB da Argentina, que tinha caído $20 \%$ entre 1999 e 2002, cresceu 8,7\% em 2003 e 9\% em 2004, e 8,6\% em 2005; o desemprego, ainda elevado, caiu de $17,8 \%$ para $10 \%$ aproximadamente; as taxas recordes de pobreza, que atingiram $57,6 \%$ em 2002, caíram para $40,2 \%$ no último ano. Como mostra o quadro, os dados positivos em relação ao crescimento são para toda a região.

América Latina e o Caribe: taxas de crescimento anuais (Em porcentagens)

\begin{tabular}{|l|r|r|r|r|}
\hline País & 2003 & $\mathbf{2 0 0 4}$ & $\mathbf{2 0 0 5}$ & $\mathbf{2 0 0 6}$ \\
\hline Argentina & 8,8 & 9,0 & $8,6^{22}$ & 6,0 \\
\hline Bolívia & 2,8 & 3,6 & 3,8 & 3,0 \\
\hline Brasil & 0,5 & 4,9 & 2,5 & 3,0 \\
\hline Chile & 3,7 & 6,1 & 6,0 & 5,5 \\
\hline Colômbia & 4,1 & 4,1 & 4,3 & 4,5 \\
\hline Costa Rica & 6,5 & 4,2 & 4,2 & 4,0 \\
\hline Cuba & 2,9 & 3,0 & 5,0 & $5 /$ d \\
\hline Equador & 2,7 & 6,9 & 3,0 & 3,0 \\
\hline El Salvador & 1,8 & 1,5 & 2,5 & 2,5 \\
\hline Guatemala & 2,1 & 2,7 & 3,2 & 4,0 \\
\hline Haiti & 0,5 & $-3,8$ & 1,5 & $5 /$ d \\
\hline Honduras & 3,5 & 5,0 & 4,2 & 4,0 \\
\hline México & 1,4 & 4,4 & 3,0 & 3,5 \\
\hline Nicarágua & 2,3 & 5,1 & 4,0 & 4,0 \\
\hline Panamá & 4,3 & 6,2 & 6,0 & 6,5 \\
\hline Paraguai & 3,8 & 4,0 & 3,0 & 3,0 \\
\hline Peru & 4,0 & 4,8 & 6,0 & 5,0 \\
\hline República Dominicana & $-1,9$ & 2,0 & 7,0 & 5,0 \\
\hline Uruguai & 2,2 & 12,3 & 6,0 & 4,5 \\
\hline Venezuela (República Bolivariana) & $-7,7$ & 17,9 & 9,0 & 5,5 \\
\hline Cone Sul & s/d & 8,4 & 7,8 & 5,7 \\
\hline Caribe & 6,5 & 4,0 & 4,1 & 5,3 \\
\hline América Latina e Caribe & 1,9 & 5,9 & 4,3 & 4,1 \\
\hline América do Sul & s/d & 6,9 & 4,9 & 4,3 \\
\hline Projar & & & & \\
\hline
\end{tabular}

(*) Projeção

Fonte: Cepal

21 "No obstante, las tasas de crecimiento proyectadas en un 4 por ciento en 2005 y un 33/4 por ciento en 2006 siguen siendo muy superiores a la media histórica." (SINGH, 2005).

22 Segundo dados oficiais do Instituto Nacional de Estadísticas y Censos (INDEC) da Argentina, o país teria crescido $9,1 \%$ em 2005. 
A Comissão Econômica para América Latina (Cepal) aponta as mesmas tendências que os relatórios do FMI. Para 2006, prevê-se a continuidade da fase expansiva do ciclo econômico. Se se confirmar a projeção de uma taxa de crescimento de 4,1\% para América Latina e o Caribe, a média de crescimento anual do período 2003-2006 será um pouco superior ao 4\% anual, e o PIB per cápita será de $11 \%$ aproximadamente. No entanto, esse crescimento seria, conforme afirma a Cepal, inferior ao conjunto dos países em desenvolvimento, cuja média seria de 5,7\% entre 2003-2006.

3. Em relação às instituiçôes financeiras internacionais, vale destacar que, assim como a Argentina, na década de 1990, era o exemplo a seguir, o show case dos defensores das reformas orientadas para o mercado e das organizaçóes internacionais, como o $\mathrm{FMI}^{23}$ e o Banco Mundial, no ano da crise econômica, 2001, o país tornou-se o exemplo paradigmático de colapso das soluções econômicas pró-mercado para uma nação em desenvolvimento. Contudo, e ainda em moratória, o governo argentino nunca deixou de pagar seus compromissos com o FMI. O resultado foi que, em 2005, já tinham sido pagos $22 \%$ da dívida que a Argentina tinha com o FMI, que passou de 14,346 bilhões de dólares em dezembro de 2001 para 11,121 bilhões em junho de $2005^{24}$. Nessa direção, o governo Kirchner seguiu os passos da Rússia e do Brasil e conseguiu a aprovação do Congresso argentino para realizar a quitação da dívida com o FMI, inclusive com a utilização de reservas do Banco Central ${ }^{25}$.

\section{Considerações finais}

O governo de Kirchner recebeu, nas eleições legislativas de outubro de $2005^{26}$, um grande apoio dos eleitores, fortalecendo sua figura no plano doméstico. Essa adesão política e os altos índices de crescimento do PIB nos últimos três anos sinalizam que haverá poucas mudanças na política externa em curto prazo, já que esta foi apresentada pelo governo como uma das chaves do presente sucesso. Por enquanto, e se a conjuntura econômica internacional favorável acompanhar o denominado "realismo pragmático" (CORIGLIANO, 2004) de Kirchner continuará a prevalecer nas negociações internacionais.

\footnotetext{
23 "A Argentina e a Turquia eram amplamente consideradas como dois dos modelos do consenso de Washington" (EICHENGREEN, 2003).

24 Jornal Clarín. 28.6.2005.

25 Jornal La Nación, www.lanacion.com.ar. Acesso: 16 de dezembro de 2005. Para uma crítica dessa decisão, desde a esquerda do espectro político da Argentina, ver: Lo Vuolo (2005). Também, em janeiro de 2006, o economista Joseph Stiglitz criticou a decisão argentina de pagar o total do montante da dívida ao FMI. Essa entrevista está disponível on line em: < http://www.lanacion.com.ar/politica/ nota.asp?nota_id=776237\&origen=ranking $>$ Acesso: 1 de fevereiro de 2006.

26 Para ver os dados detalhados das eleiçôes legislativas acessar: <http://www.mininterior.gov.ar/elecciones/ 2005/inicio.asp>
} 
Todavia, o fato de que existam, como se destacou, condições estruturais para uma maior margem de manobra por parte dos países em desenvolvimento não implicados nas novas ameaças, não quer dizer que países como a Argentina consigam ganhar maiores margens de autonomia. Tudo parece indicar que, para o século XXI, a construção de maiores margens de autonomia estaria ligada à consolidação de um bloco sub-regional ${ }^{27}$.

Com outras palavras, no caso da Argentina, o que aparece como o ressurgir do Estado-nacional, após as mostras de fragilidade do modelo econômico neoliberal, se apresenta como um conjunto de respostas pragmáticas face à globalização financeira e às frustrações desse modelo de desenvolvimento liberalizante. Essa resposta se produz num duplo plano: no plano nacional (doméstico) e no plano sub-regional. Ambas requerem arranjos políticos e alianças de classe diferentes daquelas que aplicaram e sustentaram as reformas liberalizantes nos anos 90 .

No nível regional, Buzan e Waever (2003) afirmam que os complexos de segurança regionais são os espaços de atuação primordial dos Estados, adquirindo um grau de importância inédita no período do pós-Guerra Fria ${ }^{28}$. Porém, as características desse regionalismo são diferentes na década de 90 e nos anos 2000. Nos anos 90, o processo de integração adquiriu uma modalidade denominada de "regionalismo aberto" (LIMA e COUTINHO, 2006), cujo desenvolvimento não se deveria contrapor aos princípios do livre comércio e da liberdade financeira. Nesse período, a dinâmica regional se manifestou por meio de acordos de livre comércio, em consonância com os princípios do liberalismo econômico, e de reformas de mercado adotadas pelos países periféricos da região. Esse regionalismo aberto seria uma maneira de adaptação face às vulnerabilidade externas dos Estados que tiveram sua capacidade de autonomia diminuída com a abertura econômica. Não obstante, nos anos 2000, dois desdobramentos modificaram os princípios do regionalismo aberto para uma idéia de "valorização política e física das regiōes" (LIMA e COUTINHO, 2000).

a) O primeiro processo pode ser enunciado como a crise do modelo de desenvolvimento econômico liberal, cujos primeiros indícios no plano global foram as crises do México, da Ásia, da Turquia e da Rússia na segunda metade dos anos 90 .

b) O segundo processo foi o impacto dos atentados de 11 de Setembro nos EUA, e a reformulação e reavaliação da política de segurança global a partir desse acontecimento.

\footnotetext{
27 Estamos cientes de que essa asseveração, vinculada à temática da regionalização, merece uma pesquisa de maior aprofundamento, que por razôes de espaço e tempo não podemos desenvolver neste artigo.

28 "A ordem de segurança de pós-Guerra Fria mostrará substanciais altos níveis de autonomia de segurança regional do que aquela da Guerra Fria." (BUZAN e WAEVER, 2003, p.76).
} 
$\mathrm{Na}$ Argentina de pós-crise, a política regional foi colocada, pelo governo Kirchner, num plano prioritário, elevando os vínculos com o Brasil ao status de "relações estratégicas". Essa posição objetiva inserir a Argentina como "sócio estratégico" do Brasil nas seguintes iniciativas: 1) concepção de uma estrutura mais ampla do que o Mercosul, a Comunidade Sul-americana de Naçōes (CSN) - integrada pelos países do Mercosul, o Chile e os países da Comunidade Andina de Nações: Bolívia, Colômbia, Peru, Equador e Venezuela; 2) pressão para a redução dos subsídios agrícolas que os países da União Européia (UE) outorgam a seus produtores e, no caso dos EUA, como requisito prévio para a entrada dos países do Mercosul à Área de Livre Comércio das Américas (Alca); e 3) a incorporação do Brasil como membro permanente do Conselho de Segurança das Nações Unidas (CORIGLIANO, 2004).

Desses três pontos só o segundo mostrou-se em quase total consonância com os interesses brasileiros. Em relação ao último ponto, isto é, a respeito da eventual reforma no Conselho de Segurança da ONU, existem diferenças que não são disputas conjunturais, mas posturas historicamente diferentes a respeito dessa matéria ${ }^{29}$. Em relação à gestação de uma estrutura mais ampla do que o Mercosul, a CSN, Argentina não mostrou o mesmo entusiasmo do que o Brasil, principalmente pelo papel de um e outro país no continente sul-americano. O Brasil tem pretensões de liderança regional (América do Sul) e tem utilizado o Mercosul como uma plataforma para esse objetivo de liderança, que de fato se apresenta como coordenação regional ${ }^{30}$. Por outro lado, a Argentina tem como prioridade a consolidação do Mercosul, manifestando explícita indiferença em relação à $\mathrm{CSN}^{31}$. Entretanto, essas diferenças não parecem afetar de maneira expressiva o processo de integração porque seja como um objetivo ou como um meio fundamental para atingir objetivos de liderança, a nova realidade política regional do século XXI depende muito mais do esforço das políticas estatais de seus membros do que da mão invisível dos mercados.

Recebido em 22 de março de 2006 Aprovado em 15 de junho de 2006

\footnotetext{
${ }^{29}$ Para esse ponto ver Tokatlian (2005b).

${ }^{30}$ A questão de liderança e da coordenação mereceria maior aprofundamento, mas que por razões de espaço não podemos desenvolver aqui. Contudo a noção de liderança está diretamente vinculada a graus de responsabilidades substancialmente importantes em relação ao bloco regional. Essa responsabilidade, no sentido de Kindleberger (1986) e Gilpin (2001), implica, fundamentalmente, em arcar com custos materiais face às dificuldades da integração.

${ }^{31}$ Por exemplo, a ausência dos presidentes do Paraguai, Uruguai e da Argentina na Cúpula de Cuzco, em Peru, em dezembro de 2004, para o lançamento oficial da CSN, tem que ser lido no sentido das diferenças entre os países do Mercosul enquanto às prioridades e projeções regionais e internacionais de cada um de seus membros.
} 


\section{Referências bibliográficas}

ARANDA, Ramón Alberto. La Politica Exterior Argentina: de Menem A Kirchner. IDELA/ UNT. Disponível on line: <www.idela.org> novembro de 2004. Acessado: 11.6.2005.

BERNAL-MEZA Raúl. Política Exterior Argentina: de Menem a De la Rúa. ¿ Hay una nueva Política?. São Paulo em Perspectiva, 16 (1), 2002, p. 74-93.

BERNAL-MEZA Raúl e QUINTANAR Silvia. "Argentina: entre o Mercosul e a Alca". Revista Brasileira de Politica Internacional. Ano 44, No2, 2001.

BIELSA, Rafael, LAVAGNA, Roberto, ROSSATTI, Horacio. Estado e Globalización: el caso argentino. Buenos Aires: Rubinzal - Culzoni editores, 2005.

BUZAN Barry, and Ole WAEVER, Regions and Powers. The Structure of Internacional Security. Cambridge/New York: Cambridge University Press, 2003.

Cepal. Balance preliminar de las Economias de América Latina y el Caribe. Disponível em: http://www.eclac.cl Acessado: Janeiro de 2006, vários dias.

CORIGLIANO, Francisco. "La Dimensión Bilateral de las Relaciones entre Argentina y Estados Unidos durante la Década de 1990: El ingreso al paradigma de las 'Relaciones Especiales”". In: ESCUDÉ, Carlos (Ed.). Historia General de las Relaciones Exteriores de la República Argentina. Parte IV, Tomo XV. Buenos Aires: GEL, 2003.

CORIGLIANO, Francisco. La Política Latinoamericana de Kirchner. Revista Criterio, dezembro de 2004. Disponível em: <http://www.revistacriterio.com.ar/ art_cuerpo.php?numero_id=18\&articulo_id=343\#> Acessado: 10.7. 2005.

EICHENGREEN, Barry. Crises Financeiras. Análise, prevenção e gestão. Rio de Janeiro: editora Campus, 2003.

ESCUDÉ, Carlos. Foreign Policy Theory in Menem's Argentina. Gainesville: University Press of Florida, 1997.

ESCUDÉ, Carlos. A Río revuelto: autonomía periférica en un contexto de desorden global. Agenda Internacional, Año 1 Número 1, junio-julio-agosto de 2004

Disponible en: <http:/www.geocities.com/CapitolHill/Congress/4359/autonomia.htm> Acessado: 7.5.2005.

FISHER, Stanley. Argentina Needs to Continue Fiscal and Structural Reforms, Fisher Advises. IMF Survey 30, no. 13, 2 july, 2001, p. 25-45.

GILPIN, Robert. Global Political Economy. Princeton: Princeton University Press, 2001.

HASLAM, Paul Alexander. Argentina: Governance in Crisis. FOCAL: Canadian Foundation for the Américas. Disponível on line: <www.focal.ca> fevereiro, 2003. Acessado: 14.8.2005.

IMF. World Economic Outlook. Maio, 2005. Disponível em: <http://www.imf.org/external/ pubs/ft/weo/2005/01/index.htm> Acessado: 6.7.2005.

IMF. El Contexto Mundialy lâs Perspectivas Regionales para América Latina y el Caribe, outubro, 2005. Disponível em: http: <//www.imf.org/external/np/speeches/2005/101305s.htm> Acessado: 15.10 .2005 .

KINDLEBERGER, Charles. The World in Depression 1929-1939 (revised and enlarged edition). London: University of California Press, 1986. 
LAKE, David A. e MORGAN, Patrick M., Regional Orders. Building Security in e New World, University Park: Pennsylvania State University Press, 1997.

LAVAGNA, Roberto. Política Económica y deuda. In: Bielsa et al. 2005.

LIMA, Maria Regina Soares e COUTINHO, Marcelo Vasconcelos. Integração Moderna, Observatório Sul-Americano, Análise de Conjuntura, janeiro de 2006. Disponível em: < http:/ /observatorio.iuperj.br > Acessado: 6.2.2006.

LO VUOLO, Rubén M. Pagos Anticipados al FMI: Honrar las deudas con los más fuertes, descargar su costo en los más débiles, Centro Interdisciplinario para el Estudio de Políticas Publicas, Serie Análisis de Coyuntura - No 10, diciembre, 2005.

MEARSHEIMER, John J. The Tragedy of Great Power Politics. New York: W.W. Norton Company, 2001.

MOFFETT, Matt. Latin America is Aided by Weak Dollar. Wall Street Journal, 3.12. 2004.

MOREIRA CUNHA, André e FERRARI, Andrés, A Argentina em Dois Tempos: da Conversibilidade à Reestruturação da Dívida. Mímeo. Trabalho apresentado no X Encontro Nacional de Economia Política, Campinas, SP, junho 2005.

ROMERO, Estela e TORRES, Miguel Agustín. La Constante Búsqueda de una identidad: Una mirada hacia la política exterior Argentina desde Menem a Kirchner. IDELA/UNT. Disponível on line: <www.idela.org> novembro de 2004. Acessado: 6.6.2005.

RUSSELL, Roberto. Política Exterior y veinte años de democracia: Un primer balance. In: NOVARO, Marcos, PALERMO, Vicente (Eds.). La Historia Reciente. Argentina en Democracia. Buenos Aires: Edhasa, 2004.

RUSSELL, Roberto e TOKATLIAN, Juan Gabriel. El Lugar de Brasil en la Política Exterior Argentina. Buenos Aires: Fondo de Cultura Económica, 2003.

SARAIVA, Miriam Gomes e TEDESCO, Laura. Argentina e Brasil: Políticas exteriores Comparadas depois da Guerra Fria. Revista Brasileira de Política Internacional. Ano 44, No 2, 2001, p.126-150.

SCHVARZER, Jorge. Poder político-social, condições de mercado e mudança estrutural. 2004. In: SALLUM, Brasilio Jr (Ed.). Brasil e Argentina Hoje. Politica e economia. Bauru- SP: EDUSC, 2004.

SINGH, Anoop. El Contexto Mundial y Las Perspectivas Regionales para América Latina y el Caribe. Octubre 2005. Disponible em: < www.imf.org > Acessado: 11.12.2005.

TOKATLIAN, Juan Gabriel. Hacia una Nueva Estrategia Internacional. Buenos Aires: Grupo Editorial Norma, 2004.

TOKATLIAN, Juan Gabriel. "No se gestó una estrategia internacional", reportagem no jornal Página 12, 7.5.2005(a).

TOKATLIAN, Juan Gabriel. "La Argentina, Brasil y la ONU”. jornal La Nación, 19/05/ 2005(b).

WILLIAMSON, John. "What Washington means by policy reform", in John Williamson, Latin American Adjustement: How much has happend? Washington: Institute for International Economics, 1990.

WOHLFORTH, William. "The Stability of a Unipolar World”. International Security, vol. 24 no. 1 (Summer). 1999. p. 5-41. 


\section{Resumo}

No trabalho pretende-se avaliar o período do governo Néstor Kirchner na Argentina à luz da conjuntura política e econômica internacional. Nesse sentido, pretende-se discutir se a Argentina - e os países da América Latina - tem alguma margem de manobra para a implementação de políticas alternativas ao modelo neoliberal econômico, numa conjuntura econômica favorável.

\section{Abstract}

This article intends to evaluate Néstor Kirchner government period in Argentina through the economical and political international conjuncture. In this direction, it is intended to argue whatever Argentina - and the Latin America countries - has some edge of maneuver for the implementation of alternative politics regarding the neo liberal economic model, in a favorable economic conjuncture.

Palavras-chave: Argentina, política externa, regionalismo, Mercosul.

Key words: Argentina, foreign policy, regionalism, Mercosul. 